\title{
Promoting Sustainable Construction: European and British Networks at the Knowledge-Policy Interface
}

\author{
Susan Moore ${ }^{1}$ and Yvonne Rydin ${ }^{2}$
}

\section{Keywords}

Sustainable urban development; sustainable construction; urban planning; knowledge; policy networks; Urban Thematic Strategy

\section{Acknowledgements}

The research on which this paper is based was funded by the Higher Education Funding Council for England under their HEIF2 tranche. It was undertaken within the Centre for Environmental Policy and Governance at the London School of Economics and Political Science. The authors gratefully acknowledge the financial and other support of these organisations. The authors also acknowledge the support and feedback of Rob Krueger and James Evans whose AAG 2006 session 'Engaging Critical Spaces for Sustainability' provided an initial forum for the development of this paper. We would also like to thank all our interviewees.

\footnotetext{
${ }^{1}$ School of City and Regional Planning, Cardiff University, Wales

${ }^{2}$ Bartlett School of Planning, University College London, England
} 


\section{Contact}

Dr. Susan Moore, School of City and Regional Planning,

Cardiff University,

Glamorgan Building, King Edward VII Avenue

Cardiff CF10 3WA

Moores6@cardiff.ac.uk 


\title{
Promoting Sustainable Construction: European and British Networks at the Knowledge-Policy Interface
}

\begin{abstract}
The responsibility of builders, developers, planners, architects and policy makers to promote more sustainable urban environments and buildings is consistently prioritised in nascent European, national and local planning strategies. Yet what counts as 'sustainable construction' varies by issue, sector and policy mandate. Proponents of sustainable construction might promote technological shifts in terms of materials, energy use and waste reduction, or they might encourage cultural and behavioural adaptations to how society views, uses and plans its built environment. This paper examines this problematic bifurcation of sustainable construction into two exclusive agendas: the construction technology agenda and the urban sustainability planning agenda; each constituted by distinct policy and sector-based networks. It is argued that the orientation to detail in the construction technology agenda operates at odds with the holistic process orientation of the broader urban sustainability agenda, thus complicating the effective translation or cogeneration of sustainable construction knowledge between the two networks. The lack of integration between these two sets of networks should be cause for concern, yet appears to be largely overlooked in mainstream policy processes.
\end{abstract}




\section{Introduction}

Sustainable construction has emerged as a key policy and practice sub-domain through which private sector developers and public sector decision-makers support the wider, now largely acknowledged, sustainable urban development agenda. Yet, like sustainable development before it, sustainable construction is elusive in definition and therefore patchy in its application. The term 'sustainable construction' is used to cover techniques of construction alongside matters of development and urban design. It can encompass community and accessibility concerns alongside more strictly environmental concerns. Thus, sustainable construction envelops both technological shifts in terms of the production process (e.g. materials, on-site energy use and waste reduction), as well as cultural and behavioural adaptations towards the types of buildings or environments produced as outputs (i.e. eco-homes, carbon-neutral buildings, sustainable communities etc.).

A key feature of the pursuit of sustainable construction is that it requires a mix of technical, alongside social, political and economic expertise. As Guy and Shove argue in their study of the more specific issue of energy efficiency and buildings, sustainability and the production of the built environment has often been cast in terms of a techno-economic model of technology transfer (2000, p. 57). In this linear model, research and development leads to demonstration projects, which then encourage dissemination of the new technology and take-up on a broader scale. Lack of take-up is understood in terms of barriers to the transfer process (p. 68). We follow Guy and Shove in rejecting this approach in favour of a relational, network approach in which the practices of producing the built environment are viewed as a result of complex inter-relationships between a variety of actors, the conflicts 
and congruencies of interests between actors and the framing of problems and possible solutions.

In this paper we open a particular window onto the complex relations that generate a more or less sustainable built environment, and a more or less sustainable urban development process. Here we focus on the European and British national policy and research networks that are currently involved in promoting sustainable construction. Our findings are based on 21 interviews with a range of network actors ${ }^{\mathrm{i}}$ undertaken during 2005-6, predominantly in London and Brussels. First, we set out our conceptual approach to networks and knowledge production. This is followed by the presentation of our empirical findings on the relational co-existence of two primary agendas encompassing sustainable construction issues. We consider the nature of the networks of policy, research, and industry actors involved at the European and British levels and the dynamics influencing the generation and appropriation of sustainable construction knowledge into different policy arenas. Finally, we conclude by outlining the problems that the lack of integration across the sustainable construction platform poses for both policy and industry.

\section{Sustainable Construction as Networks of Knowledge, Policy and Practice}

As we have intimated above, in our research we have rejected a rationalist perspective on technical knowledge and expertise within the policy process, in which knowledge is an object that acts as an input to that process from outside (Busenberg, 2001). Rather we take a view that such knowledge and expertise is inherently relational and constructed. What counts as technical knowledge, that is the knowledge claims that are recognised as such, are 
constructed through social relations between social actors and the material world (cf. Latour, 1999). Further, the ways that different actors relate to one another and to the material world provide the context within which knowledge claims are constructed, recognised and codified in policies. This relational view of knowledge lends itself to understanding the construction of knowledge in terms of knowledge networks (cf. Stein $e t$ $a l ., 2001)$ and the dynamics of knowledge abstraction and appropriation (cf. Guy and Shove, 2000).

Stein et al. define a network as a 'spatially diffuse structure, with no rigidly defined boundaries, consisting of several autonomous nodes sharing common values or interests linked together in interdependent exchange relationships' (2001, p. 5). Noting that the primary mandate of a knowledge network is to create and disseminate knowledge, Stein et al. identify three ways in which knowledge networks contribute to innovation and learning:

- $\quad$ They produce new knowledge through interdisciplinary research on problems as they are experienced across boundaries in different contexts;

- They produce operational knowledge, acquired through context-bound interactions between multiple sectors of expertise; and

- They disseminate knowledge by blurring the boundaries between participants and researchers, thus, ensuring that 'global' knowledge is introduced locally and that 'local' knowledge shapes and at times redefines global knowledge (2001, p. 4).

Repetitive interactions within the network and among network members are important. By their nature, such networks tend to be non-hierarchical since 'it is the absence of hierarchy 
which gives networks their flexibility, their capacity to expand and contract in response to changing environments and the potential to adapt' (Stein et al. 2001, p.5). This favours transmission within the network since knowledge is seen as coming from someone whom an actor has dealt with previously and who is considered reliable and trustworthy.

In a policy context, such as that involving the promotion of sustainable construction, the relationships involved in knowledge construction are further mediated by the relationships of the policy world. This has been described as the co-construction or co-generation of knowledge (Jasanoff 1990). Co-construction describes the process by which policy networks and the networks generating recognised knowledge mutually influence each other. That which is acknowledged as knowledge frames the policy problem and also the possible solutions; at the same time, the policy process influences what counts as knowledge in that context. Attempts have been made to specify the nature of such networks involved in co-constructing policy relevant knowledge. Of particular relevance has been the concept of epistemic communities (Haas 1992; 2004).

Epistemic communities (ECs) are seen as 'knowledge-oriented groups whose cultural standards and social arrangements revolve around a primary commitment to epistemic criteria in knowledge production and application' (Litfin 1994, p. 45). Haas describes them as a 'transmission belt of like-minded scientists' (2004, p. 576) and has emphasised that they are a 'network of professionals with recognised expertise and competence in a particular domain and an authoritative claim to policy relevant knowledge within that domain' (Haas 1992, p. 3). They are distinguished and held together by: a shared set of 
normative and principled beliefs; shared causal beliefs; shared notions of validity; and a common policy enterprise. The network of an EC is, therefore, broader than the academic scientific community and distinct from professions or disciplines. An EC is distinguished from other types of networks by the focus on knowledge and its relative autonomy from the policy process, although there may be connections to policy actors and indeed the EC is driven by a policy imperative. Thus a sustainable construction EC would describe the mix of existing research and policy actors involved in generating knowledge of sustainable construction in terms of robust and mutually accepted claims about appropriate technology and practice that would promote sustainability as a policy imperative.

The EC framework has been criticised because of its apparent separation of knowledge from political values (Litfin 1994). Litfin argues that ECs problematically see power as residing in policy domains and not as a feature of knowledge generation while Haas (2004) on the contrary argues that scientific knowledge is more credible where there is a degree of separation, even isolation from policy worlds. He places emphasis on the role of 'responsible carriers' to link the EC with those policy worlds. While the EC concept may be useful in identifying particular networks of accredited expertise in terms of their relative autonomy from policy networks, it runs the danger of seeing the policy world as a series of barriers for the penetration of knowledge (Guy and Shove 2000, p. 134) and thus replicating the techno-economic linear model of technology transfer. Instead a more fluid set of interconnections between knowledge and policy need to be investigated, starting with a stronger understanding of how sustainable construction is relationally framed and understood across multiple research and policy networks. 
It is useful here to evoke Guy and Shove's (2000, p. 38) typology for the production of knowledge in their study of the sociology of energy and buildings and apply it to our broader problematic of sustainable construction. Four component steps constitute Guy and Shove's articulation of the dynamics of knowledge abstraction and appropriation:

1. Constructing conventions;

2. Abstracting knowledge;

3. Generating knowledge; and

4. Replicating knowledge

The first component envelops consideration of the problem of framing, in our case the status quo of construction vis-à-vis 'sustainable construction'. That is to say, it is based on identifying what counts as 'sustainable' and 'unsustainable'. This process entails discussion and negotiation amongst recognised 'experts' of the methods of measurement, conventions and concepts, which they use to define sustainable construction. Here the methods of measuring actively constitute their subject (2000, p.40). According to Guy and Shove this level of knowledge production often leads to the belief that professional or technical representations of 'facts' or the current state of the environment provide a more accurate picture of what is really going on. They argue that it is this that often legitimises the extensive investment in the production of simplified toolkits and checklists (2000, p. 39), a feature that we return to below.

The next two components of the typology entail different strategies for acquiring new knowledge about sustainable construction. Through abstraction, knowledge becomes 
aggregated, generalisable and presented as applicable in a variety of contexts, i.e. transferable. Generating knowledge occurs, according to Guy and Shove, via demonstration and case study, a basis that requires benchmarks for best practice being set to promote the production of transferable and comparative evidence (2000, p. 46). Finally knowledge is replicated through the distillation and embedding of concepts and conventions into design tools and checklists that structure decision-makers' problems and 'guide cycles of iterative refinement' (p. 48). Such tools potentially impact practice, according to Guy and Shove because they draw the practitioners into a conceptual framework in which sustainable construction is given attention alongside, if not over and above other priorities (p. 49). However, the problems involved in the application and transferability to new specific sites is often glossed over.

So in our investigation of sustainable construction networks we pay particular attention to relationships between actors, the drawing of distinct networks that may include an EC and the construction of agendas and the framing of knowledge, as well as how that knowledge is being transferred and implemented by existing policy and research networks. Having outlined our conceptual approach, we now draw out the implications of our empirical work on the European and British sustainable construction networks.

\section{A Bifurcated Sustainable Construction Agenda ...}

The range of sustainable construction related policy and industry documents released through government and non-government sources over the last five to ten years 
demonstrates the lack of a consistent and concise definition for sustainable construction and a tendency towards bifurcation in the sustainable construction agenda.

At the European level, a European Working Group for Sustainable Construction was convened in 1999 at a tripartite meeting organised by the European Commission to consolidate priority actions for the construction industry under the banner of promoting the competitiveness of the sector (cf. COM(97)539). Thirteen priority actions were devised, the thirteenth action being: 'to develop a strategy for the use and promotion of environmentally friendly construction materials and energy efficiency in buildings, and waste management in order to contribute to sustainability' (WGSC 2001, p. 4). In 2001 an agenda report was produced which drew on the work of task groups on environmentally friendly construction materials, energy efficiency in buildings, construction and demolition, and construction life cycle costing. This then fed into the 2002 Directive on the Energy Performance of Buildings (CEC, 2002) with its mandating of a common methodology for calculating the energy performance of a building, new minimum standards for energy performance and systems of building certification and inspection. The work on life cycle analysis (LCA) is being developed by the Standing Committee on Construction (CEC, 2004b), which is seeking to standardise a 'European method' for the assessment of the integrated environmental performance of buildings in different sectors of the industry (cf. CEN TC350).

Also significant among the pan-European initiatives is the development of European Technology Platforms, originally defined in 2003 by the Council as 'forum[s] involving the 
main public and private stakeholders to address major technological challenges aimed at supporting the EU initiative for growth' (FIEC 2005, p. 55). This concept closely relates to the Lisbon objectives for raising competitiveness, the establishment of the 'European Research Area' (ERA) and the 'Barcelona Target' of raising the level of research expressed as a percentage of EU GDP to 3\% (FIEC 2005, p.55). The construction sector together with the research community thus initiated the European Construction Technology Platform (ECTP), which has adopted a twenty-five year Strategic Research Agenda. This has become the de facto agenda for the future of construction, largely supported by the industry and policy makers for the construction industry alike. The Strategic Agenda is based on six focus areas: Cities and Buildings; Underground Construction; Quality of Life; Networks; Materials; and Cultural Heritage. The strategic document comprises a comprehensive list of proposed actions for changing how the construction sector operates in relation to the above focus areas. It sees buildings/construction processes and urban planning as complementary areas to address but does not focus on the need to bridge these areas (ECTP Terms of Reference 2004, p. 7).

The linking of National Technology Platforms (NTPs) under the ECTP umbrella is currently being undertaken. The establishment of these national platforms, which are intended to operate in tandem with the ECTP, is viewed as a key step in creating an ERA for coordinating construction research efforts across the EU. Progress in this direction is largely credited to the work of the European Council for Construction Research, Development and Innovation (ECCREDI) and its management of the E-CORE research network, a FP5 funded project. However, there are emergent concerns that the Strategic 
Research Agenda process has been weakened due to the influence and steering of a few but powerful lobbying groups in central and southern Europe. For example, some UK stakeholders have suggested that the emphasis in the document on underground construction as a means of sustainable innovation is due to lobbying by a few strong, large construction firms in Italy and Spain. The UK stakeholders in the ECTP process were so concerned with the lobbyist influence that they recently sidestepped the Platform to provide direct feedback from Department of Trade and Industry (DTI; since our research, the DTI has been renamed the Department for Business, Enterprise and Regulatory Reform or DBERR) to the European Commission via the directorate general responsible for research (DG RTD) $)^{\mathrm{ii}}$.

Within the UK, the national platform is only just being established. While sustainability is an implicit priority of the developing national agenda, DTI's endorsement of the platform approach largely centres on its promotion of ICT, off-site construction, and modern construction methods. The DTI has also developed a sector-based strategy on sustainable construction. A first strategy was published in 2000 (DTI, 2000) and a revised version is currently under consultation (DTI, 2006). The latter is a broad ranging document that identifies six areas for improvement:

- Establishing effective construction programmes;

- Developing and supporting well focused and capable public sector clients;

- Designing and decision making based on 'whole life' value;

- Using the appropriate procurement and contracting strategies;

- Working collaboratively through fully integrated teams; and 
- Evaluating performance and embedding project learning.

At the European and national scales, therefore, this is a technical and industry-focused agenda with a strong emphasis on the different sectors within the construction industry and on standardising techniques such as Life Cycle Analysis. The sustainability agenda is largely understood in terms of innovation, such as 'modern methods' of construction and the economics of such innovation. As one of our interviewees from the UK industry perspective put it: "[Sustainable construction] seems to have been taken as meaning the same thing as innovation".

This technical/industry agenda is quite distinct from the prevailing urban planning agenda. At one point, at the European level, it appeared that there might be a meshing of these agendas. Particularly significant was the inclusion of sustainable construction as one of four themes in the consultation draft of the European Thematic Strategy on the Urban Environment (UTS) (CEC, 2004a) alongside urban environmental management, urban transport and urban design. This draft Strategy saw sustainable construction as:

'A process where all actors involved...integrate functional, economic, environmental and quality considerations to produce and renovate buildings and a built environment that is:

- attractive, durable, functional, accessible, comfortable and healthy to live in and use, promoting the well-being of all that come into contact with it - resource efficient, in particular with respect to energy, materials and water, favouring the use of renewable energy sources and needing little external energy 
to function, making appropriate use of rain and ground water and correctly handling waste water, and using materials that are environmentally friendly, that can be readily recycle or reused, that contain no hazardous compounds and can safely be disposed of

- respects the neighbourhood and local culture and heritage

- is competitively priced, especially when taking into account longer-term considerations, such as maintenance costs, durability and re-sale prices.'

The final version of the Strategy (COM2005) adopted by the Commission in January 2006 (CEC, 2006), however, was structured significantly differently. The specificity of the substantive themes above was replaced with a greater emphasis on process. In this revised version sustainable construction lost its specific prioritisation and became instead discussed in terms of its inherent but unspecified synergies with other policies within the DG Environment's remit, as well as other policy areas beyond its direct responsibility. The process of developing the UTS will be discussed further within the next section.

Returning to the British level, the Department of Communities and Local Government (DCLG; formerly the Office of the Deputy Prime Minister or ODPM) has the responsibility for planning policy guidance and building regulations. Within the DCLG the emphasis has been on encouraging planning authorities to promote sustainable development within their policy and practice. Sustainable construction is clearly an aspect of the broader goal and local planning authorities have a major opportunity to promote this through their local development frameworks and decision making on development control. At the time of our research, the policy framework for promoting sustainable construction was relatively weak. 
Planning Policy Statement 1 (ODPM, 2005) makes no specific reference to sustainable construction and where implied (i.e. in relation to mitigating climate change through planning) the examples are more spatial in nature, rather than focused on the specific nature of individual developments in the construction processes.

In December 2006, DCLG issued a package of policy documents in support of its newly announced targets that all new housebuilding should be zero-carbon by 2016; this included Towards Zero-Carbon Building, a draft climate change supplement to PPS1 and the finalised Code for Sustainable Homes which incorporates a rating scheme for new houses (DCLG, 2006a, b and c). While these represent a considerable advance in the sustainable construction agenda, there remain indicators of the structural divide between two agendas, which may undermine the implementation of the zero-carbon building initiative. These relate particularly to the divide between planning policies and building regulations.

There is specific mention within PPS 1 requiring that planning policies should not replicate the provisions of the building regulations with regard to energy efficiency (S.30) and this is repeated in the 2006 draft supplement. This suggests that promoting more technical aspects of sustainable construction should not be a primary planning function. Hence the enhanced regulations contained within the new Part L of the Building Regulations (2006) dealing with energy efficiency in new buildings is seen as rather distinct from planning functions (as indeed is the case within local authorities where a divide between planning and building control departments is common). 
The Planning and Compulsory Purchase Act 2004 was introduced in part to legislate a new purpose for planning - that of promoting sustainable development. Section 39 of the Act states that all plans must contribute to the achievement of sustainable development and must have regard to national policies and advice contained in guidance (especially PPS1). This weak formulation has been criticised for failing to give statutory weight to sustainability considerations in decision-making on planning applications for permission to develop (FoE 2004). Sustainable construction would have been boosted by such a measure.

So the urban planning agenda is much more general, process-oriented and aspirational in tone. This is in keeping with the traditional role of the planning system being to weigh up and balance alternatives with their costs and benefits, rather than unilaterally promote specific substantive goals (McAuslan, 1980). Yet, while urban planning may prioritise holistic change over and above the technical means of delivering it, industry interests focused on sites and buildings find it difficult to comprehend and act on holistic 'urban' environment issues. For a sector historically devoted to technological innovation in material 'things', the construction industry is now finding itself pressed to deliver not merely efficient and safe homes and smart offices but dauntingly a 'sustainable built environment'. Few industry actors, save those that are the 'big players' in the international engineering, design and development fields, such as Arup, or developers capable of delivering largescale holistic tenders, such as Crest Nicholson, have yet to embrace the social and economic dimensions of sustainable construction in their daily operations and RTD.

\section{[INSERT TABLE 1 AROUND HERE]}


Our interviews revealed that this bifurcation at the level of documentation, specific policies and initiatives between a technical/industry agenda and an aspirational and generalised urban planning agenda is also apparent in the expressed understandings of key policy and industry actors. Table 1 summarises relevant quotes from our interviews and shows that there are two different constructions of sustainable construction as an issue at work here. There was a third position taken by some interviewees, namely a general aversion to defining the term was also expressed. The following quotes illustrate this:

"I am suspicious about trying to define sustainable construction other than to say it is innovation towards certain directions" (UK, Industrial Federation representative).

"Sustainable construction is an empty container, devoid of meaning, other than shared definitions amongst certain stakeholders. So it is crucial to get those stakeholders to 'fill' the empty vessel each time it is used" (UK/EU Research Consultant).

"Why do we need to define it? It is a waste of time to bother...do we need a definition unless it is for a legal document? I say forget about definitions because it is almost everything. But, if pressed for it, a broad definition is construction activities from a different perspective" (EU Industrial Federation representative).

"That is a tough question, how do you define sustainable construction? Because what is sustainable construction...construction by its very essence is using 
resources, and ideologically resource use is not sustainable" (EU Professional Association representative).

These quotes reflect back interestingly on Guy and Shove's typology of knowledge generation with the construction of the issue as the first stage. Here we have some refusal to engage in such a framing of the issue. However, these are in the minority and there is, in the documentation as well as amongst the majority of interviewees, essentially two competing framings.

This bifurcation will have an impact on the ability of technical knowledge to penetrate the policy process affecting urban development more broadly since co-production of policy and knowledge will be limited by the lack of a dialogue between these agendas. There are some discursive grounds for the limited success in promoting the sustainable construction agenda. First, the lack of integration results in a failure to address all problems of the implementation of sustainable construction methods and techniques. Second, it ignores the aggregate impact of design and management decisions at the site or project level on the macro urban environment level, which is a primary concern of urban planning. Third, industry by and large remains unprepared (strategically and practically), with some exceptions, to deliver a 'sustainable built environment' due in part to its predisposition to consider only the technical side of environmental innovation; whilst the urban planning agenda expects industry to improve the overall performance of built environments without clearly defining the limits and standards that industry requires to benchmark its progress. With this background, we now move on to consider how these discourses of the policy agenda relate to the dynamics of knowledge and policy networks. 


\title{
...And Distinct Policy and Research Networks
}

\author{
"there are networks for everything in Brussels" (UK, local government \\ representative)
}

Our interviews with research and policy actors in Brussels and London suggest that there is an emerging but still limited pan-European epistemic community on sustainable construction. They demonstrated that a web of programmes and initiatives on construction technology and standardisation within the industry exist. While implicitly about sustainability, many initiatives are much more driven by construction technology trends and commercial considerations. Furthermore, these networks are separated from those concerned with broader urban planning at both the European and British levels. The networks thus underpin and reinforce the discursive structure of the agenda(s) surrounding sustainable construction. Figure 1 provides a simplified illustration of the network; the following section explains some of the complexities of this structure.

\section{[INSERT FIGURE 1 AROUND HERE]}

At the European level, DG Enterprise (DG ENTR) is both the focal point for one of the networks and its instigator. As described above, DG ENTR initiated the 1999 tripartite meeting which led to the creation of four task groups on sustainable construction culminating in the 2001 Sustainable Construction Agenda Report. Crucially DG ENTR 
brought together industry and the research community via the task groups [which then had a direct influence on the work of DG Transport and Environment (DG TREN) on the Energy Performance of Buildings Directive]. These two sectors - industry and the research community - had previous experience working together via the formation of the European Council for Construction Research, Development and Innovation (ECCREDI) in 1995. This Council was established as a joint initiative of the construction industry and the research community, with its general aim 'to contribute to the competitiveness, quality, safety and environmental performance of the construction industry and to the overall sustainability of the built environment, particularly through the promotion of research.' As one representative from a member organisation stated in our interview: "ECCREDI brought together the contractors, research institutes, architects, engineers, material producers, even social housing associations into a council that thinks about research requirements in Europe." This is close to the textbook definition of an epistemic community and suggests that this network has at least the potential characteristics of such an EC.

The 2001 Agenda Report coincided with the launching of the E-CORE (European Construction Research Network) under the FP5 research programme 'Competitive and Sustainable Growth'. E-CORE initially provided an electronic reference point for construction research at a EU level, 'providing an 'umbrella' for individual research interests and for specialist networks related to construction to come together and share ideas and opportunities'(E-CORE 2005 at http://www.e-core.org/strategy.). More recently E-CORE has developed a strategy for European construction research, identifying gaps and proposing priorities for future EU programmes 
The work of ECCREDI and the E-CORE objective of developing a research strategy and prioritising future EU funding opportunities were key drivers in the formation of the European Construction Technology Platform, with its own 25 year Strategic Research Agenda and a fledgling collection of National Technology Platforms (NTP). In the UK this NTP is supported through DTI/DBERR and Constructing Excellence, as is Avanti, which is an ICT-enabled collaborative working programme under ERAbuild. ERAbuild is the European Research Area on sustainable construction and operation of buildings. Its longterm aim is to prepare a trans-national $\mathrm{R} \& \mathrm{D}$ programme in the area. A short term goal for the project is the development of a learning network of governmental organisations.

DG ENTR also covers the sustainability angle on construction minerals and aggregates and have a database on regulations across Europe on different products. This echoes a key theme of the work of the DG which is the emphasis on standardisation across Europe with a view to ensuring a commercial 'level playing field', seen as essential to the successful operation of the common European market. The work on standardising the accreditation of the environmental performance of building materials and products is now being run out of DG Environment (DG ENV) but this started out in DG ENTR because, as one of our interviewees from the industry stated, the Commission wanted "environmentally friendly sectoral credentials", and thought this would work better by starting with a "friendly" DG from the perspective of the industry. Work was then taken over by DG ENV. DG Energy and Transport (DG TREN) has the energy remit within the Commission; their position is that there should be $R \& D$ on the urban environment and long term impact of buildings but, 
according to one of our interviewees from DG TREN, they have asked the EC to let the energy performance of buildings directive have a chance to settle in and take root in the industry before doing much more in this regard.

Alongside the technology- and industry-led emergent EC run a larger number of European networks which are more diffuse in nature working on policy and research initiatives related to urban sustainability and planning. At the European level these include the European Sustainable Towns and Cities Campaign, the activities of the Expert Group on Urban Sustainability and a variety of $5^{\text {th }}$ and $6^{\text {th }}$ Framework Research Programme projects (e.g. TISSUE; DISCUS; ACTOR; STATUS; LASALA). Many of these projects are/were focused on delivering toolkits, often using ICT, to enable monitoring and strategy development from the perspective of the holistic goal of urban sustainability. Interviews with actors involved in the technical detail of construction methods and procedures and those involved in these urban sustainability-oriented networks underscored the limited integration currently existing between these two sets of networks.

This is compounded, according to some interviewees, by the variable nature of urban 'planning' as a concept and the presumed existence of professional 'planners' across Europe. Outside of the UK the dominance of 'planners' as a key profession is marginal. Greater emphasis is often placed on urban design, with architects, or more broadly speaking urbanists, taking lead roles in the design and construction specifications for the built environment. Yet, a mix of opinions was expressed by interviewees in relation to the presence of architects in sustainable construction policy networks. Some industry 
representatives suggested that architects were "the key group of wafflers, with a lot to talk about, but not leading to anything real" (Interview EU Industrial Federation Representative); while still others felt the presence of architects in forums and discussions on sustainable construction in Europe was not explicit enough given that they "seem to be the ones who get to specify the materials" (Interview EU Industrial Federation representative).

The European focal point for these networks is DG Environment (DG ENV). However, urban planning is an area where the issue of subsidiarity looms large. The European Union has no formal competence in the area of urban planning, unlike on environmental issues. This clearly affects the Commission's approach to this issue and the desire to suggest a cascade of policy down from the European level but with responsibility and action occurring at the national and local levels. Hence the urban planning networks largely revolve around the actions and interactions of local government networks and organisations. This too sets it apart from the technical agenda and suggests that the urban planning agenda is perceived to be a public sector issue, not of primary concern to industry actors. The emphasis on the public sector role of delivering a more sustainable urban environment underpinned the production of the EU Thematic Strategy on the Urban Environment (UTS), whose implementation largely depends on the commitment of local authorities to operationalise local strategic management frameworks.

'Local authorities have a decisive role in improving the urban environment. The diversity in terms of history, geography, climate, administrative and legal conditions calls for locally developed, tailor-made solutions for the urban environment. 
Application of the subsidiarity principle, where action should be taken at the most effective level, also implies action at the local level' (CEC 2006, p. 3).

The process of developing the UTS is itself a noteworthy example of the interface of policy and research networks attempting, with questionable results, to operate across the bifurcated sustainable construction agenda. The UTS originated as part of the $6^{\text {th }}$ Environmental Action Programme as one of seven thematic strategies introduced to 'provide a holistic approach to key environmental issues that are characterised by their complexity, the diversity of actors concerned and the need for innovative and multiple solutions' (CEC 2004a, p. 3). UK stakeholders in the UTS process have suggested, however, that this was the last of the seven thematic strategies (i.e. an afterthought); it had the smallest profile and the "least teeth". Prior to the 2004 Communication 'Towards a Thematic Strategy on the Urban Environment' (CEC 2004a), in consultation with the EU Expert Group on the Urban Environment four priority themes were identified. Sustainable construction was one of these. The Sustainable Construction Methods and Techniques (SCMT) working group was set up in 2003. Several of those interviewed were members of the working group, expressing varying opinions on its significance and impact.

Following the 2004 Communication, sustainable construction was removed as a priority theme and only the three remaining areas were carried forward and dealt with via the formation of three Expert Technical Working Groups. Sustainable construction, as one SCMT member noted following the release of the final Communication on the UTS (CEC 2006) "is effectively gone from the urban thematic strategy." A UK government 
stakeholder commented, however, that the inclusion of sustainable construction was always fairly insignificant because, given the Commission's structure, the issue fell out of the jurisdiction of DG ENV, and was the remit of another Directorate General (i.e. DG ENTR). Still other interviewees commented on the degree of "inter-service consultation" surrounding the UTS; European code for ministerial disagreement which has been cited as a contributing factor in the eventual rewriting and watering down of the UTS. The latter was partially attributed to the impact of a general shift towards the Centre Right within the Commission occurring around 2004, leading to the domination of the competitiveness agenda across all of the Directorate Generals' work plans.

Two high profile industry federation representatives from Brussels involved in the SCMT meetings expressed very strong opinions on the futility of the working group's efforts from their perspective.

"I left it because it was a waste of time. It as just like talking to a brick wall."

"I went to the first meeting, and I am usually someone characterised as provocative and interruptive, but I didn't say a word. ... I just sat there listening to high quality waffle."

Other interviewees commented specifically on the nature of the Working Group's composition and division of labour.

"It was not well composed. Most of those on the group knew each other and there was not much fresh input from certain areas, particularly the commercial interest areas, until late in the process" (EU/UK Academic). 
In addition, interviewees suggested that the working group members did not have much time to put into the process other than to attend meetings and that there was little scope for the devolution of work for members to do beyond the meetings. Another Research Consultant from the UK suggested that the SCMT reports became so edited down in significance that they exist now as little more than an annex, listing the actors involved. Some of the editing down was undoubtedly due to the restrictions on length imposed for all Strategies by the Commission.

"There was a cap on the number of characters allowed and the technical annexes are only published in English. The final document was boiled down and boiled down to the point where I have to remind myself what stayed v. what was cut"(DG Environment representative).

Beyond this however, the negative reaction to the 2004 Communication from the local government level (particularly in the UK) to the proposed mandatory requirement for urban management and transport plans also led to the eventual weakening of the Strategy through invoking the subsidiarity principle so that it came to focus on voluntary measures.

The UTS is also interesting for the number of key organisations and bodies, on both sides of the technical-planning divide that were unaware of its existence. A representative from Constructing Excellence stated that: "very few people knew that it was happening. Certainly I wasn't aware until afterwards". Other agencies interviewed speculated that they may not have responded to the consultation precisely because of the "urban label". For example, a representative from an arms length government agency in the UK was unaware of any formal response and suggested that because the topic was "urban" it was not as 
tangible and related to their expertise as would be the case for issues like air quality or water pollution. What we see is that even where there is a public sector effort to engage with the technical framing of a policy issue and efforts made to convene a working group representative of pan-European construction sector interests little real integration is enabled through the current mechanisms used by policy networks.

Meanwhile at the national level, while central responsibility for sustainable development lies with DEFRA (Department of Environmental Food and Rural Affairs) it is the organisational division between the DTI/DBERR and DCLG that largely reinforces the separation of networks. Current UK policy offers us a clear illustration of how the lack of integration between the two sustainable construction agendas can manifest and impact future policy development.

“We've got a lack of joined up thinking between government departments and even within government departments" (Interview with Constructing Excellence).

The DTI is pursuing the technological modernisation of the construction industry for reasons of economic competitiveness. Meanwhile the DCLG is implementing the Sustainable Communities Plan (2003) as its flagship policy. This defines sustainability largely in social terms, with an emphasis on developing significant new urban areas either through growth on brownfield and some green field sites in the south of England or through demolition and redevelopment in the north. It is operating in the context of calls for more housebuilding (cf. Barker Report 2004) to meet demographic forecasts and bring house prices into a range of affordability. The result is, mounting pressure on the planning system to deliver more development rather than stop and consider innovation in the kind of 
development promoted and how it is delivered. The current housebuilding target is 3 million new homes by 2020. The Egan Review (2004) did address the skills needed to implement the Sustainable Communities Plan and here there is some overlap with the responsibilities of the DTI/DBERR but this does not seem to provide a strong link in the agendas of the two departments. The impact of the Egan Review, particularly its recognition of the need not only for professional and technical skills in planning and building but also for a range of generic skills, behaviours and knowledge - including investor risk-taking, and local authority leadership and partnership working - has largely been outsourced to the Academy for Sustainable Communities based in academe although with the involvement of a range of stakeholders.

The DTI/DBERR is sponsoring a micro-generation and low carbon buildings initiative (DTI, 2005), focused on the production of heat and/or energy on a small scale and from low carbon sources. This follows on from the government's 2003 Energy Strategy and the requirements of the 2004 Energy Act; it should also connect with Planning Policy Statement 22 on renewable energy although this document deals mainly with the planning implications of larger-scale renewable energy projects. Crucially, it is not yet apparent how this initiative will mesh with the promotion of development under the Sustainable Communities Plan. While there is mention of the need for new green technologies in the Sustainable Communities development projects, it is generally agreed that the emphasis within the DCLG agenda has not prioritised the environmental. Comments made by a representative of the former ODPM support this: 
"The ODPM is in the firing line on environmental issues. There is a lot associated with construction but the Sustainable Communities Plan is about housing not construction which is controversial. The Sustainable Communities Plan is associated with house building - the environment is an afterthought - the stress is on social sustainability. So now we are in a process of playing catch up with the environmental dimensions."

The sentiment was also expressed by staff member of an environmental quango in the UK that the agency's mandate is now to "retrofit' sustainable construction back into the Sustainable Communities Plan.”

This division between DTI/DBERR and DCLG is reflected in the different constellation of organisations, professions and lobby groups around the departments. Around DTI/DBERR are found CITB (the Construction Industry Training Board), RIBA (Royal Institution of Chartered Architects), CIC (Construction Industry Council), CIRIA (Construction Industry Research and Information Association), and BRE (Building Research Establishment); while around DCLG are RTPI (Royal Town Planning Institution), RICS (Royal Institution of Chartered Surveyors), Planning Officers' Society, local authorities and their representative organisations, various environmental and urban NGOs and BRE. BRE stands out as having links with both departments. And while DEFRA has little direct interest in sustainable construction, it has acted as the focal point for a UK-Sweden initiative (See Box 1). However, it is the role of Constructing Excellence within this initiative that is largely feeding its outcomes back into policy and practice. 


\section{[INSERT BOX 1 AROUND HERE]}

\section{The dynamics of knowledge generation and appropriation}

These problems of lack of integration reflected and rooted in the network structures influence the flow and impact of knowledge on sustainable construction. We conclude the analysis by considering some of these dynamics of knowledge flows.

One feature is the dearth of knowledge brokers and spanners; i.e. those who work to improve the handling and circulation of knowledge within these complex networks with their varying agendas. In the UK, Constructing Excellence stood out in this regard as the only self-acknowledged 'broker', and was also identified as such by other interviewees. There does not seem to be an equivalent organisation taking up the broker role in the European context. ECCREDI might be considered in this light but it is itself a network, an EC rather than a broker within and between networks. Most brokering rather seems to occur within specific projects and initiatives not across the sustainable construction policy issue. The lack of knowledge brokers able to effectively link the EU and national, the technical and the policy networks is critical to the dissemination and translation of knowledge into formats appropriate to the various different actors involved in promoting sustainable construction in different contexts. The lack of knowledge brokers and spanners involved in the prioritisation of sustainable construction has meant that the various checklists and codes have not been as effectively devised and used as anticipated. This is in part due to the lack of individuals and agencies charged with taking knowledge with them 
from the domain of policy learning (where epistemic and policy networks ideally overlap) to the domain of organisational learning within firms, specific agencies and local authorities, thereby effectively transforming the knowledge into something that is usable and appropriate to everyday practice.

However, there are other features of the networks and how they operate that hinder the consolidated efforts towards more sustainable construction practices. These are largely rooted in the economics of the construction industry. Firstly, the interviews suggested as well that the sustainable construction knowledge networks that do exist (both in Britain and Europe) are increasingly commercially driven. It was noted by several interviewees that commercial interests in 'green building' are eclipsing academic or expert-driven knowledge development as a public good. More emphasis is being placed on intellectual property rights and the commercialisation of green specifications and performance indicators. This is occurring in part due to the EU promotion of the marketisation of knowledge as part of an economic competitiveness agenda towards a European Knowledge Economy.

Second, the economic structure of the construction industry has a major influence, particularly the dominance of sectoral divisions and divisions within the supply chain. The production of sustainable construction knowledge is currently segmented along these lines (e.g. housing, industrial, retail and commercial, or procurement, energy, materials, design, performance etc.) This may make it more difficult to connect the commercially driven networks of technology-oriented sustainable construction with those of public sector planning, which takes a more holistic approach to urban areas. The piece-meal management 
of sustainable construction knowledge on an issue-by-issue technical basis is divided up amongst different sectors within the construction industry as a whole, while the strategic vision is largely left to government departments working within their own policy networks and bureaucratic silos. There is "so much compartmentalisation that no one is responsible for the gaps" (Interview UK/EU Research Consultant). The result being that any 'usable knowledge' (to follow Haas, 2004) on sustainable construction is either overly technical or procedurally diluted. As one UK research consultant put it: "the problem is that planners do not see construction as a vehicle to deliver sustainability and the construction and building industry does not see its role in social development or dictating behavioural change." The sectoral approach is reinforced by the current emphasis on mandatory CE Marking for construction products introduced by the Construction Products Directive (89/106/EEC). The aim is for each product to have an EPD or environmental product declaration prepared on a life cycle costing basis. CEN TC350 Sustainability in Construction works will create a further set of horizontal European standards to address the integrated performance of buildings, but this is still in the pipeline.

Third, there are the pressures emanating from the industry for a light touch on regulation and for codes, etc. to be voluntary. Certainly there is much in the literature from DTI/DBERR and DCLG/ODPM that could lead to the conclusion that sustainable construction is largely a matter for the construction industry itself to innovate and selfregulate, and for building inspectors to consider when enforcing building regulations. One could further argue that this laissez-faire approach is reinforced by central government's emphasis on demonstration projects (e.g. BedZED, South London) and best practice 
schemes (e.g. BREEAM, EcoHomes; Code for Sustainable Homes), which rely on exhortation rather than regulation to spread sustainable construction. Achieving specified levels within the Code for Sustainable Homes (CSH) is now mandatory for publicly-funded housing and CSH rating will be mandatory for new housing in 2008, but requiring private new housing to achieve specified levels will be introduced incrementally through adjustments to the Building Regulations.

A representative from the UK Home Builders Federation put the case against the use of regulation:

"Ours is a risk taking industry - in that we have to work within the regulatory environment and deal with a mass retail market. The risk here is what you can do with consumers on a commercial basis. Even if the regulatory system facilitates innovation there is no guarantee that consumers will be interested in this. It is not a cost thing in terms of environmental standards and products, but a cultural thing." Industry representatives largely favour a performance-based standards system as the route to sustainability targets because they provide a commercial context" (Interview UK Industry Federation representative). Regulations, on the other hand, are seen as becoming overly prescriptive, not only by way of setting minimum standards but in dictating to industry how to achieve them. The sentiment expressed by many in industry that they "don't believe in unnecessary regulation" surely influences the hesitance and cynicism of industry stakeholders invited to participate in policy networks like those of the SCMT working group for the UTS. The view from industry on regulation was summarised by one representative of the building sector as: 
"There is some evidence of a change in government thinking towards a new approach to performance objectives but not specifying how you get them. This allows for more creative options which also relate to commercial efficiency. There is a need for a regulatory environment that empowers innovation. Positive outcomes should be outlined but not how to get there. This keeps the door open. In this sense, less is more. But I would caution that local authorities cannot foresee the best ways forward and that they should leave it to those in the market who can see mass consumer or commercial ways to innovate and deliver on the objectives."

The DTI/DBERR has largely backed the concerns of industry with regard to the market directing innovation in construction. It was stated by DTI/DBERR representatives interviewed that:

"the DTI holds a strong position on the need for industry to steer the knowledge cycle improvements and that less legislation (in other words de-regulation) via better quality regulations could simplify the processes needed and actually act as a driver for innovation."

This fits with the DTI/DBERR's specific remit of a sponsorship role for the construction industry, a role which might be seen as conflicting with putting pressure on the industry to change in a more sustainable direction. The apparent conflict is squared by suggesting that what drives innovation is the taking of calculated risks. The market should therefore lead and the public sector needs to be less risk adverse. 
Other researchers on sustainable construction practice within industry have noted, however, that there is a significant contingent of stakeholders (both public and private sector oriented) with a 'strong appetite for regulation and enforcement, backed up by taxes and financial incentives' (Cooper 2006, p. 14). In addition, these advocates for regulatory measures, according to Cooper 'commonly identif[y] central government, particularly the ODPM and the Treasury - often aided by local planning authorities - as primarily responsible for initiating the actions required' $(2006$, p. 14). Secondary responsibility is seen by these same stakeholders as lying with those involved in the procurement of buildings along with training and professional organisations (p. 15).

A further aspect of the current regulation of the industry through the planning system was highlighted by interviewees who saw construction professionals and their state regulators as existing in a largely adversarial relationship. This was bound to lead to great difficulty in collaborating, even on an agreed shared objective. The lack of communication between regulators and practitioners was illustrated by some interviewees as a function of the lack of feedback loops at the policy-practice interface. For example, one interviewee commented: "Planning regulations and laws that relate to building design and construction are not evidence based, therefore there are no feedback loops and there is no continued duty of care or responsibility beyond the planning application and building permit process"(Interview UK/EU Research Consultant).

Industry also has mixed views on local authority leadership. While this is seen as important, in terms of having a clear strategic vision, there should be limits on how much 
power local authorities wield. Particular mention was made of the general lack of confidence that public authorities have in the private sector to deliver sustainable projects. This lack of trust is believed to hinder the planning approval process. So much so that sustainable construction-conscious development interests often decide it is not worth pursuing such projects in a given locale and will move on to somewhere more receptive and cooperative: “...if planners don’t understand what sustainable construction is all about and what developers can deliver, they are not going to let sustainable developments go through" (Interview with Constructing Excellence). The often adversarial nature of relations between developers and local authorities might prove a significant barrier to the partnership working deemed necessary by Egan (2004), for the successful delivery of sustainable, masterplanned communities.

There are, thus, two distinct agendas circulating around the issue of sustainable construction. These are reflected in and reinforced by distinct networks with different organisational bases. Two cultures of learning and innovation exist within the policy and industry networks; one that privileges holistic and iterative change and one that operates on the basis of performance objectives and benchmarks. Perhaps most significantly, strong economic imperatives - based on sectoral division and attitudes to risk, innovation and regulation - keep the industry agenda and networks apart from those concerned with broader urban planning, charged with delivering a more sustainable built environment in general terms. 


\section{Conclusion}

This paper has focused on the rise of the sustainable construction agenda and the significance of networks in the sustainable construction policy context. We have provided evidence that highlights the extent and significance of the bifurcation into two exclusive agendas - an industry-led technology agenda and a broader aspriational urban planning agenda - each constituted by strong policy networks. The lack of integration between these two sets of networks should be cause for concern, and yet it appears to be largely overlooked in the policy process. The orientation to detail in the construction technology agenda operates at odds with the holistic process orientation of the broader urban sustainability agenda, thus complicating the effective translation or co-generation of knowledge between the two networks. Bridging this disconnect will necessarily involve delivering mechanisms for sustainable construction that satisfy the technological imperative whilst avoiding the tokenism often ascribed to the urban sustainability planning discourse.

While there is only space to suggest some ways forward briefly, the above analysis would suggest a need for more knowledge spanners operating within, and crucially across, the different networks. These may work most effectively in specific locales and on specific projects where goal-oriented communities of practice (Wenger, 1998, 2002) might be created. But given the importance of the economic context for the generation and appropriation of sustainable construction knowledge, market-based measures will also be important. These might include: fiscal measures to prioritise sustainable construction (through VAT or property taxes); more consumer information (labelling and certification schemes); and more investment in labour market measures to support successful sustainable 
construction. There is also the role of more stringent yet streamlined regulation to drive technology forward. While these are demanding changes, the goal of sustainable urban development is an important one and this suggests that some investment of policy effort would be worthwhile to ensure that the structures and dynamics of agendas and networks do not frustrate its achievement. 


\section{References}

Barker K. 2004. Review of Housing Supply: Delivering stability, securing our future housing needs. HM Treasury: London.

Busenberg G. 2001. Learning in organizations and public policy. Journal of Public Policy. 21(2): 173-189.

Commission of the European Communities. 1997. The Competitiveness of the Construction Industry. $\mathrm{COM}(97) 539$.

Commission of the European Communities. 2002. Directive on the Energy Performance of Buildings. Directive 2002/91/EC.

Commission of the European Communities. 2004a. Towards a Thematic Strategy on the Urban Environment. COM(2004)60 Final.

Commission of the European Communities. 2004b. Development of Horizontal

Standardised Methods for the Assessment of the Integrated Environmental Performance of Buildings $\mathrm{M} / 350$.

Commission of the European Communities. 2006. Thematic Strategy on the Urban Environment. COM(2005)718 Final3. 
Cooper I. 2006. Developing a robust framework for measuring the contribution of the construction industry to sustainable development. Unpublished draft paper provided by author.

Department of Communities and Local Government. 2006a. Towards Zero-Carbon Building, consultation draft. DCLG: London

Department of Communities and Local Government. 2006b. PPS1 - Climate Change Supplement, consultation draft. DCLG: London

Department of Communities and Local Government. 2006c. Code for Sustainable Homes. DCLG: London

Department of Trade and Industry. 2000. Strategy for Sustainable Construction: Building a Better Quality of Life. DTI: London.

Department of Trade and Industry. 2005. Micro-generation Strategy and Low Carbon Buildings Programme: consultation. DTI: London.

Department of Trade and Industry. 2006. Sustainable Construction Strategy Report 2006. DTI: London. 
European Construction Research Network (E-CORE). 2005. E-Core Strategy for

Construction RTD: Executive Summary. Available at: http://www.e-core.org/strategy/ (Accessed 31/10/06).

European Construction Technology Platform (ECTP). 2004. European Construction Technology Platform ECTP Building for a Future Europe: Terms of Reference. Available at: http://www.ectp.org/documentation/ECTP_Terms_of_Reference_Dec_20_2004.pdf (Accessed 31/10/06).

Egan Review. 2004. Skills for Sustainable Communities. ODPM: London.

FIEC (European Construction Industry Federation). 2005. Аnnual Report 2005. FIEC: Brussels.

Friends of the Earth. 2004. Housing: Building a Sustainable Future (Response to the House of Commons Environmental Audit Committee supplementary questions from Friends of the Earth). FoE: London.

Guy S, Shove E. 2000 A Sociology of Energy, Buildings and the Environment: constructing knowledge, designing practice. Routledge: London.

Haas P. 1992 Introduction: epistemic communities and international policy coordination. International Organization 46(1): 1-35. 
Haas P. 2004. When does power listen to truth? A constructivist approach to the policy process. Journal of European Public Policy 11(4): 569-592.

Her Majesty's Government. Planning and Compulsory Purchase Act 2004. The Stationary Office: Norwich.

Jasonoff S. 1990. The Fifth Branch: science advisers as policy maker. Harvard University Press: Cambridge, MA.

Latour B. 1999. Pandora's Hope: Essays on the reality of science studies. Harvard University Press: Cambridge, MA.

Litfin K. 1994 Ozone Discourses: Science and politics in global environmental change. Columbia University Press: New York.

McAuslan P 1980. The Ideologies of Planning Law. Pergamon: Oxford.

Office of the Deputy Prime Minister. 2003. Sustainable Communities: Building for the future. ODPM: London.

Office of the Deputy Prime Minister. 2004. Planning Policy Statement 22: Renewable Energy ODPM: London. 
Office of the Deputy Prime Minister. 2005. Planning Policy Statement 1: Delivering Sustainable Development. ODPM: London.

Stein J, Stren R, Fitzgibbon J, MacLean M (eds). 2001. Networks of Knowledge: collaborative innovation in international learning. University of Toronto Press: Toronto.

Wenger E. 1998. Communities of Practice: learning, meaning and identity. Cambridge University Press: New York, NY.

Wenger E. 2000. Communities of Practice and social learning systems. Organization 7(2): $225-246$.

Working Group on Sustainable Construction (WGSC). 2001. Competitiveness of the Construction Industry: An agenda for sustainable construction in Europe (A report drawn up by the Working Group for Sustainable Construction with participants from the European Commission, Member States and Industry). Available at:

http://www.ceetb.org/docs/Reports/Sust-con-final.pdf (Accessed 31/10/2006). 
Table 1: Interviewees' construction of sustainable construction

\begin{tabular}{|l|l|}
\hline Technical industry-led framing & Urban planning-led framing \\
\hline $\begin{array}{l}\text { 'Sustainable construction needs to be about } \\
\text { the technical side of sustainability - about } \\
\text { durability but also about standardisation but } \\
\text { from a materials-based approach rather than a } \\
\text { sectoral approach.' (EU Industry Federation } \\
\text { representative) }\end{array}$ & $\begin{array}{l}\text { Construction is a very important aspect of } \\
\text { performance of buildings and their impact } \\
\text { on the wider environment.' (EU } \\
\text { Directorate General representative) }\end{array}$ \\
\hline $\begin{array}{l}\text { 'Sustainable construction is primarily energy } \\
\text { efficiency and conservation, with a strong } \\
\text { emphasis on renewables. But it also considers } \\
\text { materials at the level of the individual } \\
\text { components going into a building ... (UK/EU }\end{array}$ & $\begin{array}{l}\text {... but there is also a whole other issue in } \\
\text { relation to the neighbourhood level which } \\
\text { brings in cross-boundary issues like } \\
\text { transport, housing and planning.' (UK/EU } \\
\text { Academic) }\end{array}$ \\
\hline $\begin{array}{l}\text { 'Sustainable construction involves so many } \\
\text { players, so many networks but it is often } \\
\text { discussed (by government and industry) from } \\
\text { the perspective of energy and energy } \\
\text { efficiency.' (UK QUANGO representative) }\end{array}$ & $\begin{array}{l}\text { 'Sustainable construction is the responsible } \\
\text { use of resources, and the responsible } \\
\text { integration of those resources into durable, } \\
\text { uplifting, high quality spaces and } \\
\text { architectures both inside and outside.' (EU } \\
\text { Professional Association representative) }\end{array}$ \\
\hline $\begin{array}{l}\text { 'There is a convergence of an understanding } \\
\text { that sustainable construction is any innovation } \\
\text { or best practice that leads towards improved } \\
\text { performance of a building or impacts the } \\
\text { supply chain.' (UK Industry Federation } \\
\text { representative) }\end{array}$ & $\begin{array}{l}\text { Sustainable construction is part of } \\
\text { sustainable development. It is the nuts and } \\
\text { bolts side of sustainable development.' } \\
\text { (UK QUANGO representative) }\end{array}$ \\
$\begin{array}{l}\text { 'It is different things to different people. } \\
\text { Modern methods of production are high on } \\
\text { the agenda.... But there is a wide definition of } \\
\text { modern methods too, so it seems to have been } \\
\text { taken as meaning the same thing as } \\
\text { innovation.' (UK Industry Federation } \\
\text { representative) }\end{array}$ & \\
\hline
\end{tabular}




Box 1 - Joint UK-Sweden Initiative for Sustainable Construction
The formation of the Joint Initiative in 2004 was preceded by initial interactions
between DEFRA and the Swedish Ministry of Sustainable Development in
discussions on environmental technologies, in response to the EU Environmental
Technology Action Plan*. The concentration on construction was targeted because it
was agreed that the environmental technology needed to improve the environmental
performance of construction was generally available in both the UK and Sweden (and
Europe generally) but what was lacking was the take-up and dissemination of best
practice. So the impetus for the Joint Initiative was one of supporting improved
knowledge transfer potential. In addition to supporting the dissemination of best
practice the Joint Initiative was formed to establish new businesses and business links
in both countries. Constructing Excellence acts as the UK secretariat for the
Initiative's Steering Group and hosts its website:
http://www.constructingexcellence.org.uk/uksweden/default.jsp
* http://ec.europa.eu/environment/etap/index_en.htm

${ }^{\mathrm{i}}$ Interviewees from the European Commission included officials from DG TREN, DG ENV, DG ENTR and DG Research; from UK Central Government: ODPM (International Planning Unit and Corporate Strategy and International Division); from Local Government: Local Government Association/International Bureau, Association of London Government/Greater London Enterprise, London's European Office; from trade and industry: UK Home Builders Federation, European Construction Industry Federation, Council of European 
Producers of Materials for Construction; from Professional Associations: Architect's Council of Europe; from QUANGOs: Constructing Excellence, Environment Agency, CITB-Construction Skills; and several academic and commercial consultants (including Ove Arup and Eclipse Research Consultants).

ii The bureaucracy of the European Commission is organised into DGs or Directorates General, each with a specific remit. 